\title{
Amplitude of the rest-activity cycle in chronic obstructive pulmonary disease: an exploratory study
}

\author{
Emilie Chan-Thim ${ }^{1-3}$ \\ Marie Dumont ${ }^{3,4}$ \\ Gregory Moullec 3,5 \\ Zohra Parwanta ${ }^{2,3}$ \\ Barbara Trutschnigg ${ }^{3}$ \\ Jean Paquet ${ }^{3}$ \\ Veronique Pepin ${ }^{2,3}$ \\ 'Individualized Program, School of \\ Graduate Studies, ${ }^{2}$ Department \\ of Exercise Science, Concordia \\ University, ${ }^{3}$ Research Center, Hôpital \\ du Sacré-Coeur de Montréal, \\ ${ }^{4}$ Department of Psychiatry, Université \\ de Montréal, Montreal, ${ }^{5}$ Department \\ of Psychoeducation and Psychology, \\ Université du Québec en Outaouais, \\ Gatineau, QC, Canada
}

Correspondence: Marie Dumont Chronobiology Laboratory (J-5I85), Sacré-Coeur Hospital of Montreal, 5400 Gouin Boulevard West, Montreal, QC H4J IC5, Canada $\mathrm{Tel}+\mathrm{I} 5 \mathrm{I} 43382222$ ext 2246 Fax +| $5|4338253|$ Email marie.dumont@umontreal.ca
This article was published in the following Dove Press journal:

ChronoPhysiology and Therapy

21 October 2016

Number of times this article has been viewed

Abstract: In chronic obstructive pulmonary disease (COPD), there is large individual variability in the progression of the disease. Low amplitude of rest-activity rhythms has been associated with worse prognosis in a variety of diseases, but it has not been investigated in COPD. The first aim of this exploratory study was to compare disease severity and prognosis indicators between COPD patients with relatively high or low amplitude of their rest-activity cycle, as measured with actigraphy. As a second objective, 24-hour profiles of both activity levels and nighttimesleep quality were compared between the two subgroups to assess the relative contribution of day- and night-activity levels to high and low rest-activity rhythm amplitude in this population. Rest-activity rhythms were measured with 8-14 days of wrist actigraphy in 14 patients (nine men), aged 58-79 years, suffering from moderate-to-severe COPD. Relative amplitude of 24-hour activity profiles ranged from 0.72 to 0.98 . Participants were divided at the median into high-amplitude (mean \pm standard deviation $0.9 \pm 0.04$ ) and low-amplitude $(0.79 \pm 0.05)$ subgroups. There was no significant difference between the two subgroups for pulmonary function or exercise capacity. However, the low-amplitude group had more severe symptoms of dyspnea and worse prognostic scores than the high-amplitude group $(P<0.05)$. The 24-hour activity profiles revealed higher levels of activity in the high-amplitude group for the $12-3 \mathrm{pm}$ interval $(P<0.05)$. There was no significant difference between the two groups for subjective or actigraphic estimates of sleep quality, sleep duration, or proportion of daytime sleep. This exploratory study is a first step toward the identification of larger rest-activity rhythm amplitude as a marker of better prognosis in COPD and as another potential target for exercise-based rehabilitation programs in this population.

Keywords: actigraphy, accelerometry, circadian rhythms, COPD, respiratory disorders, prognosis, physical activity, sleep

\section{Introduction}

Studies on a variety of medical disorders, including cancer, ${ }^{1}$ Alzheimer's disease, ${ }^{2,3}$ and hypertension, ${ }^{4}$ have found that larger amplitude in rest-activity rhythms is associated with lower disease severity and better prognosis. Rest-activity rhythms are usually measured with continuous actigraphic recordings, a technique that has the advantage of being noninvasive and providing results that are representative of patients' usual behavior. In a recent review, Truong et $\mathrm{al}^{5}$ clearly demonstrated the impact of circadian rhythms in respiratory diseases. However, their review also highlighted the scarcity of literature on this topic in chronic obstructive pulmonary disease (COPD). To our knowledge, the association between amplitude of the rest-activity cycle and disease severity and prognosis has not been investigated in COPD patients. 
COPD is a respiratory disorder that develops over time and is progressive by nature. It is a leading cause of morbidity and mortality worldwide. ${ }^{6}$ The most common cause of COPD is the inhalation of noxious particles, such as cigarette smoke. Airflow is obstructed by such factors as inflammation in the bronchioles, mucus hypersecretion, and destruction of the lung parenchyma, leading to the collapse of the alveoli and gas trapping in the lungs. ${ }^{7}$ Destruction to the lungs cannot be reversed with current therapy; therefore, the management of COPD aims to control symptoms and slow down the progression of the disease. ${ }^{8}$ The severity of COPD is traditionally measured by the degree of airflow limitation and the presence of respiratory symptoms (dyspnea, cough, phlegm, or wheezing), which have both been associated with increased mortality. ${ }^{9}$

The progression of COPD is typically manifested by a decline of about $30-60 \mathrm{~mL}$ per year in forced expiratory volume in 1 second $\left(\mathrm{FEV}_{1}\right) .{ }^{10-12}$ However, the rate of decline in lung function in COPD is not uniform, and the progression of the disease is quite variable among patients. For instance, individuals who experience frequent exacerbations (more than two per year), a worsening of their respiratory symptoms usually caused by a respiratory infection, have demonstrated a faster rate of decline. ${ }^{13}$ Life-threatening exacerbations have been associated with a phenotype that includes low body mass index (BMI), low exercise capacity, high dyspnea score, and severe airflow obstruction. In this respect, a composite index combining these four indicators, the BODE (BMI, airflow obstruction, dyspnea, exercise capacity) index, has been developed and used as a good predictor of mortality risk in COPD patients. ${ }^{14}$ BODE index prognosis value is further improved when supplemented with a comorbidity index, the Comorbidity Test (COTE) index, in which other conditions commonly associated with COPD (eg, cardiovascular disease, depression, sleep apnea) are integrated into a weighted score. ${ }^{15,16}$

In a study published in $2014,{ }^{17}$ we reported the impact of time of day on exercise capacity in 14 COPD patients, studied using a counterbalanced repeated-measure design. Patients were evaluated three times over a period of 8-14 days, during which they filled out sleep and mood diaries and underwent continuous actigraphic recordings. Mood data were published in $2016 .{ }^{18}$ For the present paper, we took advantage of actigraphic data to explore the possible difference in diseaseseverity and prognosis indices between COPD patients with relatively high or low amplitude in rest-activity rhythm, with the expectation of finding lower severity and better prognosis in the subgroup of patients with larger amplitude. We adopted the approach chosen by Bromundt et al, ${ }^{19}$ who used median amplitude to split a sample of schizophrenia patients into subgroups of lower and higher amplitude of rest-activity rhythms to compare their levels of cognitive functioning. As a second objective, actigraphic data were also used to compare profiles of 24-hour activity levels and indicators of nighttime-sleep quality between the two subgroups to evaluate their respective contribution to high and low amplitude of rest-activity rhythms in this population.

\section{Materials and methods Participants}

Fourteen patients with diagnosed COPD were recruited at the Hôpital du Sacré-Coeur de Montréal over an 8-month period. Recruitment was based on information reported in medical records. All patients were clinically stable and presented with moderate $(n=12)$ or severe $(n=2)$ airflow obstruction according to GOLD (Global Initiative for Chronic Obstructive Lung Disease) classification criteria: ${ }^{20}$ postbronchodilation $\mathrm{FEV}_{1}$ less than $80 \%$ of the predicted normal value, and $\mathrm{FEV}_{1}$ to forced vital capacity (FVC) ratio less than $70 \%$. All patients were aged 40 years or older, had a smoking history of at least 10 pack-years (20 cigarettes per pack), and had prior exercisetesting experience. Exclusion criteria were: 1) a respiratory exacerbation in the past 4 weeks, as reported by the patient at recruitment and at the beginning of the study (change in dyspnea or volume/color of sputum, need for antibiotic or systemic corticosteroid treatment, or hospitalization); 2) active condition other than COPD that could influence exercise tolerance; 3 ) need for oxygen therapy; and 4) prescribed theophylline. The local ethics research committee of Hôpital du Sacré-Coeur de Montréal approved the research project, and all participants signed an informed consent prior to taking part in the study. Detailed description of clinical characteristics and inclusion/exclusion criteria for the participants is provided in a previous publication. ${ }^{17}$

\section{Study design and procedure}

Data presented in this paper were collected in a study evaluating the impact of time of day on acute response to incremental exercise in COPD patients, and detailed methodology has been published in a previous publication. ${ }^{17}$ Briefly, the study required four hospital visits, 8-14 days of actigraphy, and a sleep-wake diary. At visit 1, BMI and baseline pulmonary function were measured, and depression and anxiety symptoms were assessed using the Center for Epidemiological Studies - depression (CES-D) questionnaire ${ }^{21}$ and the Beck Anxiety Inventory (BAI), ${ }^{22}$ respectively. Visits 2-4 were scheduled at least 36 hours apart, included pulmonary function and exercise tests, and were identical except for the 
time of day ( $8 \mathrm{am}, 12 \mathrm{pm}$, or $4 \mathrm{pm}$ ). Patients were asked to withhold respiratory medication for at least 6 hours before each visit. Ambulatory activity recording and sleep diaries were initiated at visit 1 and ended at visit 4 . Comorbidities and dyspnea level were obtained from medical records.

\section{Evaluation of disease severity}

Three measures were used to assess COPD severity: a subjective measure of dyspnea, an objective measure of pulmonary function, and a measure of peak exercise capacity. Participant dyspnea levels were obtained from medical records, as ascertained during the respirology appointment closest to the study (range 0-15 months, median 1 month). These were measured with the modified Medical Research Council (mMRC) dyspnea scale. ${ }^{23,24}$ The mMRC dyspnea scale is a 5-point scale that corresponds to statements related to physical activity and level of breathlessness: grade 0 , breathless with strenuous exercise; grade 1, short of breath when hurrying on level ground or walking up a slight hill; grade 2, walks more slowly than people of the same age on level ground, and experiences breathlessness or the need to stop to catch breath when walking on level ground at their own pace; grade 3, stops to catch breath after walking about $100 \mathrm{~m}$ or after a few minutes on level ground; and grade 4, too breathless to leave the house, or breathless when dressing and undressing. ${ }^{23}$

Pulmonary function was assessed at visit 1 with spirometry using cardiometabolic equipment (Oxycon Pro; BD, Franklin Lakes, NJ, USA). All patients were evaluated between 10:30 am and $3 \mathrm{pm}$. Spirometry was performed with the patient seated, as per recommended procedures. ${ }^{25}$ At least two to three normal tidal breaths were taken, followed by a maneuver where a full inspiration of air was immediately followed by a full and forceful expiration, until maximal expiration was reached. The total volume of air expired during the maneuver was recorded as FVC, and the volume expired within the first second of expiration was recorded as the $\mathrm{FEV}_{1}$. The maneuver was repeated to obtain three acceptable tests, and the best value obtained for $\mathrm{FEV}_{1}, \mathrm{FVC}$, and of $\mathrm{FEV}_{1}: \mathrm{FVC}$ ratio was recorded. In addition to absolute values, measures were normalized to account for differences in sex, age, and height for a Caucasian population, using the predicted normal values from the European Community for Coal and Steel/European Respiratory Society. ${ }^{26}$ The resulting value of $\mathrm{FEV}_{1} \%$ predicted was used to classify the severity of airflow obstruction.

Exercise capacity was evaluated at visits 2-4 using an electromagnetically braked cycle ergometer (Ergoselect 200P; Ergoline GmbH, Bitz, Germany), with participants connected to cardiometabolic equipment (Oxycon Pro).
Participants performed symptom-limited incremental cycling exercise tests according to a standard protocol. ${ }^{27}$ Testing began with 5 minutes of rest and 3 minutes of unloaded pedaling, and then the workload was increased in a stepwise manner by 5-10 W every minute up to the individual's maximal capacity. Standardized instructions were given prior to each test, and verbal encouragement given during the test was standardized at every 30 seconds. Maximal exercise capacity was recorded as the highest workload achieved and maintained for at least 30 seconds at a pedaling rate of 50 revolutions per minute. Peak oxygen consumption $\left(\mathrm{VO}_{2 \max }\right)$ was calculated for each test as average $\mathrm{VO}_{2}$ obtained over the last 30 seconds of the test. The mean of the results obtained at the three visits was then expressed as a percentage of the predicted normal value according to sex, age, and weight. ${ }^{28}$

\section{Evaluation of disease prognosis}

Two measures were used to evaluate disease prognosis: the BODE index and the COTE index. The BODE and COTE scores were also summed to form a composite score, which has been demonstrated to be a better predictor of mortality than individual scores alone. ${ }^{15,16}$

The BODE index is a composite measure of body composition, airflow obstruction, dyspnea rating, and exercise capacity. The following elements account for the traditional BODE index: BMI as the measure of body composition, $\mathrm{FEV}_{1}$ (\% predicted) as the measure of airflow obstruction, mMRC score as the dyspnea rating, and distance walked on a 6-minute walking test as exercise capacity. ${ }^{14}$ In the present study, a modified BODE index (mBODE\%) was calculated, where percent $\mathrm{VO}_{2 \max }$ was used as a measure of exercise capacity in replacement of 6-minute walking distance. This approach has been proposed and previously validated by Cardoso et al. ${ }^{29}$ Scores on the mBODE\% index range from 0 to 10 , indicating low to high risk of death, respectively. ${ }^{14,30}$

The COTE index was calculated based on information reported verbally by the participant during the hospital visits and completed by a review of the participant's medical records. The COTE index categorizes comorbidities into 12 domains found to be associated with an increased risk of mortality in COPD patients: ${ }^{15}$ oncologic (lung, pancreatic, esophageal, and breast cancer), pulmonary (pulmonary fibrosis), cardiac (atrial fibrillation/flutter, congestive heart failure, coronary artery disease), gastrointestinal (gastric/duodenal ulcers, liver cirrhosis), endocrine (diabetes with neuropathy), and psychiatric (anxiety). Each of these comorbidities is associated with a specific score. The final COTE score can range from 0 to $25,{ }^{16}$ and a score $>4$ has been linked with an increased mortality risk. ${ }^{15}$ 


\section{Evaluation of amplitude of rest-activity cycle}

Activity recordings were conducted with an actigraph equipped with an event marker (Actiwatch 2; Philips, Amsterdam, Netherlands). The monitor was worn on the nondominant wrist, 24 hours per day, for a minimum period of 8 consecutive days (range 8-14 days). Participants were instructed to press the event marker at bedtime, when ready to sleep, and upon waking in the morning. Periods of nonwear of the actigraph monitor (eg, for bathing) were identified using the sleep-wake diaries and then excluded from the data. Further missing data were visually identified and removed based on the following published criteria: when more than $50 \%$ of the activity was missing per hour, the entire hour was excluded from the analyses, ${ }^{31}$ and when 3 or more hours were missing in the 24-hour period, the entire day was excluded. ${ }^{19}$ The mean of 1-minute data was calculated for each valid hour of recording, and then the 1-hour means were averaged for each clock hour across the days of recording to obtain a 24-hour profile.

To estimate amplitude of the rest-activity rhythm, we calculated relative amplitude (RA), a nonparametric indicator that makes no assumptions about the shape of the rhythm..$^{32}$ The 10 consecutive most active hours of the day and the 5 consecutive least active hours of the night were identified from the 24 -hour profile. RA was then calculated as the ratio of activity during the 10 most active hours minus activity during the 5 least active hours over the sum of activity during the 10 most active and 5 least active hours.

\section{Comparison of 24-hour activity levels}

Using the approach of Bromundt et al, ${ }^{19}$ activity counts were log-transformed and collapsed into 3-hour bins. Resulting profiles were then compared between patients with higher and lower RA to determine the presence of differences between the two groups of patients.

\section{Evaluation of nighttime-sleep quality}

One-minute actigraphic data were also used to estimate some indicators of nighttime-sleep quality. Data were scored with dedicated software (Actiware version 5.7; Philips) using a medium wake threshold (40 activity counts). For each data set, the actogram was visually inspected and compared with the participant-reported times via the event marker and sleep diaries. For each night of recording, bedtime and wake time were set using information from the sleep-wake diaries, data from the event marker, and visual inspection of the actogram. The interval between bedtime and wake time defined the duration of time in bed. Other variables were computed by the software, and included 1) sleep latency (number of minutes between bedtime and sleep onset, with sleep onset defined as the beginning of the first 10 consecutive minutes of sleep), 2) total sleep time (total number of minutes scored sleep), and 3) sleep efficiency (total sleep time divided by duration of the sleep episode $\times 100$ ). Sleep efficiency was the main variable used as an objective estimate of sleep quality.

\section{Sleep-wake diaries}

On each day of ambulatory recording, participants filled a sleep diary to report bedtime and wake time, as well as presence and duration of daytime naps. These reports were used to calculate the subjective estimate of total duration of sleep per 24 hours and the percentages of daytime sleep in the total 24-hour sleep. Subjective sleep quality was reported using a Likert scale from very bad (1) to very good (5) quality.

\section{Statistical analyses}

The 14 participants were split into two groups of seven patients having higher or lower rest-activity rhythm amplitude, using median RA as a threshold. ${ }^{19}$ Data normally distributed were compared between the two groups using Student's $t$-test. Analysis of covariance (ANCOVA) was used to control for age in comparisons yielding significant group differences. Comparisons of 24-hour activity profiles were conducted using a group-by-time $(2 \times 8)$ analysis of variance (ANOVA) adjusted with Huynh-Felt correction for repeated measures (original degrees of freedom are reported). Results are presented as mean \pm standard deviation, and the level of significance was set at $P<0.05$. Analyses were performed using SPSS version 23.

\section{Results}

\section{Participants}

Participants comprised nine men and five women aged 58-79 years ( $71 \pm 7$ years). Clinical characteristics of the 14 participants are presented in Table 1. All participants had moderate-to-severe COPD, and most had a moderate mMRC dyspnea index score (index of 2). The average time since diagnosis was $5 \pm 3$ years, and eleven ( $79 \%$ ) participants were retired. All participants had previously been smokers, and two (14\%) remained active smokers. Twelve participants (86\%) were using short-acting anticholinergic medication at the time of the study. Nine participants (64\%) used combination products of long-acting $\beta_{2}$-agonists and inhaled corticosteroids. 
Table I Clinical characteristics of the 14 participants

\begin{tabular}{|c|c|c|}
\hline Variable & Number/mean \pm SD & Range \\
\hline COPD stage (II/III/IV) & $12 / 1 / 1$ & II-IV \\
\hline mMRC dyspnea score $(2 / 3 / 4)$ & $8 / 3 / 3$ & $2-4$ \\
\hline $\mathrm{FEV}, \%$ predicted & $58 \pm 13$ & $23-76$ \\
\hline $\mathrm{FEV}_{1} / \mathrm{FVC}(\%)$ & $53 \pm 11$ & $38-75$ \\
\hline $\mathrm{VO}_{2 \max } \%$ predicted & $72 \pm 14$ & $46-96$ \\
\hline BMI $\left(\mathrm{kg} / \mathrm{m}^{2}\right)$ & $27 \pm 4$ & $22-35$ \\
\hline $\mathrm{mBODE} \%$ index & $3 \pm 2$ & $1-7$ \\
\hline COTE index & $I \pm I$ & $0-4$ \\
\hline BODE + COTE & $4 \pm 3$ & $1-8$ \\
\hline
\end{tabular}

Abbreviations: SD, standard deviation; COPD, chronic obstructive pulmonary disease; $F E V_{1}$, forced expiratory volume in I second; FVC, forced vital capacity; mMRC, modified Medical Research Council; $\mathrm{VO}_{2 \max }$, maximal oxygen consumption; mBODE, modified BODE (BMI, airflow obstruction, dyspnea, exercise capacity; index using $\mathrm{VO}_{2 \max } \%$ predicted); COTE, comorbidity test (COPD-specific); BMI, body mass index.

\section{Amplitude of rest-activity rhythm and COPD severity and prognosis}

RA ranged from 0.72 to $0.98(0.84 \pm 0.07)$. The RA mediansplit cutoff in our sample was 0.855 . Mean RA was 0.79 $( \pm 0.05)$ in the low-amplitude group and $0.9( \pm 0.04)$ in the high-amplitude one. Comparisons of clinical variables between the two groups are presented in Table 2. Respiratory function ( $\mathrm{FEV}_{1} \%$ predicted) and exercise capacity $\left(\mathrm{VO}_{2 \max } \%\right.$ predicted) did not differ significantly between the two groups, but the low-amplitude group had more severe symptoms of dyspnea (mMRC score) and worse prognosis according to COTE and BODE + COTE scores compared to the highamplitude group. There was no significant difference between the two groups for BMI.

Both age and psychological distress can influence clinical variables. Participants of the low-amplitude group were significantly older ( $75 \pm 5.2$ years) than participants of the

Table 2 Comparison of clinical variables (mean \pm SD) between participants with high or low relative amplitude of the restactivity cycle

\begin{tabular}{|c|c|c|c|}
\hline Variable & $\begin{array}{l}\text { Low relative } \\
\text { amplitude } \\
(<0.855)\end{array}$ & $\begin{array}{l}\text { High relative } \\
\text { amplitude } \\
(\geq 0.855)\end{array}$ & P-value \\
\hline mMRC dyspnea score & $3.14 \pm 0.9$ & $2.14 \pm 0.38$ & 0.026 \\
\hline FEV, \% predicted & $58 \pm 7.77$ & $57.71 \pm 17.29$ & 0.97 \\
\hline $\mathrm{VO}_{2 \max } \%$ predicted & $67.4 \pm 12.37$ & $76.37 \pm 14.86$ & 0.24 \\
\hline BMI & $28.8 \pm 4.3$ & $25.5 \pm 3.6$ & 0.15 \\
\hline mBODE\% index & $3.86 \pm 1.57$ & $2.43 \pm 2.15$ & 0.18 \\
\hline COTE index & $1.7 I \pm I .5$ & $0.29 \pm 0.49$ & 0.046 \\
\hline BODE + COTE & $5.57 \pm 1.72$ & $2.7 I \pm 2.43$ & 0.026 \\
\hline
\end{tabular}

Abbreviations: SD, standard deviation; mMRC, modified Medical Research Council; $\mathrm{FEV}_{1}$, forced expiratory volume in I second; $\mathrm{VO}_{2 \max }$, maximal oxygen consumption; BMI, body mass index; mBODE, modified BODE (BMI, airflow obstruction, dyspnea, exercise capacity; index using $\mathrm{VO}_{2 \max } \%$ predicted); COTE, comorbidity test (COPD-specific). high-amplitude group $(67.9 \pm 6.6$ years $)(P=0.04)$. When controlled for age using an ANCOVA, group differences remained significant for $\mathrm{mMRC}$ dyspnea score $(P=0.02)$ and BODE + COTE score $(P=0.049)$, but not for COTE score $(P=0.06)$. Psychological screening questionnaires yielded similar results between the two groups for depression (CES-D scores $12.9 \pm 10.3$ vs $11.3 \pm 9.9$ in low- and high-amplitude groups, respectively; $P=0.78$ ), and were not significantly different for anxiety (BAI scores $10.4 \pm 6.8$ vs $8 \pm 7.2$ in low- and high-amplitude groups, respectively; $P=0.18$ ).

\section{Amplitude of rest-activity rhythm and 24-hour activity levels}

ANOVA showed no significant group effect $\left(F_{1,12}=0.86\right.$, $P=0.37)$, but the group-by-time interaction was significant $\left(F_{7,84}=2.53, P=0.02\right)$. Simple-effect analyses revealed higher levels of activity in the high-amplitude group in the interval $12-3 \mathrm{pm}(P=0.03)$, with a similar trend for the interval 9 am-12 pm $(P=0.08)$. Results are illustrated in Figure 1.

\section{Amplitude of rest-activity rhythm and sleep timing and quality}

For each participant, reported sleep variables represent values averaged over 6-12 days of recording (mean 9.1 \pm 2.6 days). One participant from the low-amplitude group did not complete the sleep diary on all days; therefore, subjective sleep quality and diurnal sleep to total 24-hour sleep are available for only 13 subjects. On average, participants were in bed from 10:49 pm ( \pm 37 minutes) to 6:51 am ( \pm 49 minutes), with a sleep-onset latency of $22.3( \pm 17.8)$ minutes and a sleep efficiency of $85.6 \%( \pm 6.8 \%)$. Partici-

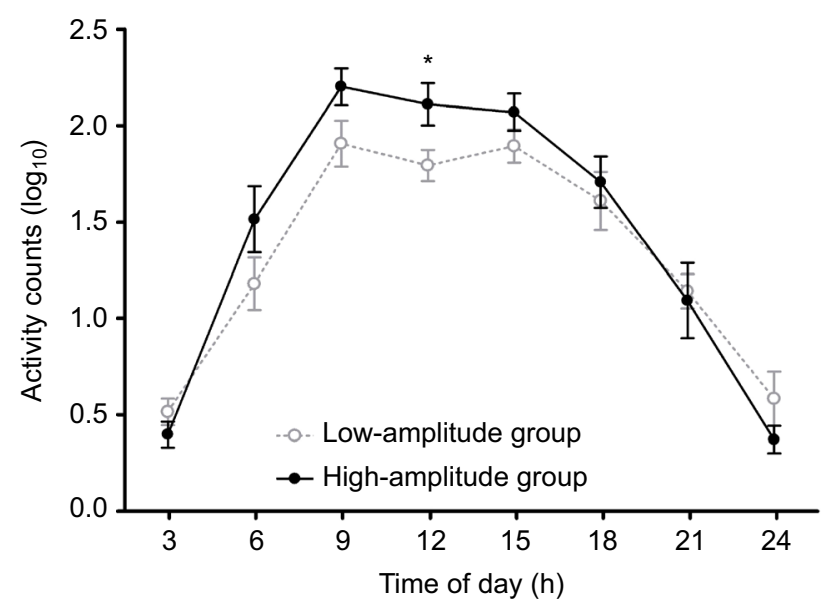

Figure I Activity counts (mean \pm standard deviation of log-transformed data). Notes: Counts averaged for the next 3 hours (eg, data reported at $3 \mathrm{~h}$ represent mean activity counts measured between 3 and $6 \mathrm{am}$ ) for patients divided at the median into low and high relative amplitude groups ( $n=7$ in each group). Asterisk indicates significant group difference $(P=0.03)$, for the $12-3 \mathrm{pm}$ interval. 
Table 3 Comparison of sleep variables (mean \pm standard deviation) between participants with high or low relative amplitude of the rest-activity cycle

\begin{tabular}{|c|c|c|c|}
\hline Variable & $\begin{array}{l}\text { Low relative } \\
\text { amplitude } \\
(<0.855)\end{array}$ & $\begin{array}{l}\text { High relative } \\
\text { amplitude } \\
(\geq 0.855)\end{array}$ & $P$-value \\
\hline Bedtime (24-hour clock) & $22: 51 \pm 00: 25$ & $22: 48 \pm 00: 49$ & 0.86 \\
\hline Wake time (24-hour clock) & $07: 08 \pm 00: 54$ & $06: 34 \pm 00: 41$ & 0.2 \\
\hline Time in bed (hours) & $8.3 \pm 0.8$ & $7.7 \pm 0.9$ & 0.24 \\
\hline Sleep latency (minutes) & $24.5 \pm 21.6$ & $20.0 \pm 14.6$ & 0.65 \\
\hline Total sleep time (minutes) & $382 \pm 64$ & $379 \pm 63$ & 0.95 \\
\hline Sleep efficiency (\%) & $82.8 \pm 6.5$ & $88.4 \pm 6.2$ & 0.13 \\
\hline Subjective sleep quality ${ }^{a}$ & $3.7 \pm 0.4$ & $3.9 \pm 0.3$ & 0.5 \\
\hline Total 24-hour sleep (minutes) & $535 \pm 65$ & $5 I I \pm 7 \mid$ & 0.53 \\
\hline Diurnal/24-hour sleep (\%) & $6.76 \pm 4.22$ & $6.85 \pm 5.55$ & 0.98 \\
\hline
\end{tabular}

Notes: a Data from sleep diaries. Subjective sleep quality scored I (very bad) to 5 (very good).

pants reported fair-to-good subjective sleep quality (range 3.17-4.31). Ten participants (77\%) reported daytime naps, with a mean duration of $49 \pm 21$ minutes. Table 3 presents the comparisons of sleep variables between low- and highamplitude groups. There was no significant group difference for either actigraphic measures or subjective estimates of sleep timing and quality.

\section{Discussion}

The main objective of this paper was to compare disease severity and prognosis indices in COPD patients with lower or higher amplitude of rest-activity rhythm. Significant differences between subgroups of low and high RA were found for dyspnea severity and for the combined prognosis score BODE + COTE, but not for respiratory function or exercise capacity. Differences were in the expected direction, with patients with lower RA for rest-activity rhythms displaying greater symptom severity and worse prognosis.

There is currently no accepted threshold to determine a "normal" level of RA for rest-activity rhythms. However, using a median split to divide our group of patients into high- and low-amplitude subgroups, we obtained a threshold of 0.855 , similar to the threshold of 0.85 , also found with a median split, by Bromundt et a ${ }^{19}$ in their group of 14 middleaged schizophrenia patients. Moreover, the mean RA in our high-amplitude group (0.9) was similar to theirs (0.93) and was also similar to the median amplitude (0.91) they observed in an independent group of 23 healthy individuals slightly younger (64 \pm 5.4 years) than our participants. In another study, a mean RA of $0.86( \pm 0.02)$ was reported in ten older ( $73 \pm 1.5$ years) healthy men. ${ }^{32}$ RA higher than 0.85 thus seems to be representative of healthier older individuals, but larger studies will be needed to determine a valid "normal" threshold in different age-groups.

Many factors may contribute to decreased amplitude of rest-activity rhythms, an important one being older age. ${ }^{33,34}$ We found that participants in the low-RA group were significantly older than those in the high-RA group. However, there was no significant difference in age between patients with moderate (mMRC score $2, \mathrm{n}=8$, age $70.3 \pm 7.3$ years) or severe (mMRC score $3-4, \mathrm{n}=6$, age $73 \pm 6.4$ years) dyspnea symptoms $(P=0.48)$. Furthermore, group differences in both dyspnea score and BODE + COTE prognosis index remained significant when the effect of age was taken into account in ANCOVA. Statistical control is very limited in this small number of subjects, but our results suggest that the age difference was not the main factor that explains the differences in dyspnea symptoms and prognosis between the two RA subgroups. Among other factors previously associated with lower amplitude of rest-activity rhythms are high $\mathrm{BMI}^{35}$ and symptoms of depression and anxiety. ${ }^{36-38}$ In the present study, there was no significant difference between the highRA and low-RA subgroups for BMI nor for psychological distress evaluated with validated questionnaires. Because of the limited statistical power in this study, a contribution of these variables cannot be completely excluded, but they do not appear to be major factors explaining increased dyspnea symptoms and worse prognosis in the low-amplitude group.

Low amplitude of rest-activity rhythms may reflect disturbed nocturnal sleep and/or decreased daytime activity; both have been found to be associated with decreased amplitude in healthy aging. ${ }^{33}$ Presumably in COPD, symptoms of breathlessness associated with severe dyspnea could result in more nighttime awakenings ${ }^{39}$ and in turn reduce rest-activity amplitude by increasing nighttime activity. Other medical conditions associated with worse prognosis, as assessed with the COTE index, may also decrease nighttime-sleep quality. However, sleep quality and total sleep time were not significantly different between our two subgroups of high and low RA. In Bromundt et al, ${ }^{19}$ with the same number of subjects, it was clearly greater nighttime activity that characterized their low-RA group $(P<0.001)$. In our group of COPD patients, ANOVA rather identified lower daytime-activity levels as the main factor contributing to low amplitude, especially at midday (Figure 1). As our two subgroups were very similar for total 24-hour sleep time and proportion of daytime sleep (Table 3), increased napping in patients included in the low-RA group does not seem likely. Therefore, the amplitude difference between the two subgroups appears to have been due to increased physical activity at midday in the high-RA subgroup. 
While a direction of causality cannot be established in this study, it can be hypothesized that patients with more severe symptoms of dyspnea and more comorbidities were more sedentary, leading to reduced levels of daytime physical activity and decreased amplitude of rest-activity rhythms. Indeed, reduced physical activity levels in COPD have been associated with increased dyspnea ratings on the mMRC scale, ${ }^{40}$ comorbid chronic illnesses, such as heart disease and type 2 diabetes, ${ }^{41,42}$ and a worse score on the BODE index..$^{40,43} \mathrm{In}$ our COPD patients, respiratory function ( $\mathrm{FEV}_{1} \%$ predicted) and exercise capacity $\left(\mathrm{VO}_{2 \max } \%\right.$ predicted) were not statistically different between low-RA and high-RA subgroups, suggesting that it was not the severity of airflow obstruction that was restrictive for daytime activity. Symptoms of dyspnea were more severe in the low-RA subgroup. However, symptoms of dyspnea are usually worse in the morning, ${ }^{44,45}$ and we observed differences in daytime activity, mostly in the early afternoon. Therefore, more than just symptoms of dyspnea may have been influencing the amplitude of the rest-activity rhythm in our COPD patients.

Increased comorbidity in our low-RA group is consistent with reduced amplitude of the circadian rest-activity cycle reported in other disease conditions, such as hypertension, ${ }^{4}$ cancer, ${ }^{1}$ and mood disorders, ${ }^{46}$ all conditions taken into account by the COTE index. In their study of schizophrenia patients, Bromundt et $\mathrm{al}^{19}$ found that low amplitude could be associated with disturbances of circadian rhythms, as shown by a delayed onset of melatonin secretion in relation to sleep time, and they proposed that circadian asynchrony may explain the strong association they found between low amplitude and low scores on many tests of cognitive functions. There were no measures of endogenous circadian markers in the present study, but sleep timing and duration were in the normal range and similar in the two amplitude subgroups. Therefore, there was no indication of an abnormal circadian phase in the low-RA subgroup. The only indication of a possible circadian dysfunction was the lower RA. Low amplitude of rest-activity rhythms has been found to be an independent prognostic factor for cancer patients' survival, ${ }^{38}$ suggesting the possibility of a two-way relationship between circadian amplitude and severity of clinical symptoms.

This study was an exploratory investigation of clinical differences between COPD patients with higher or lower amplitude of the rest-activity rhythm. This exploration was conducted on patients recruited for a broader study with different aims. ${ }^{17}$ As such, the study has some limitations, including a relatively small sample size and the absence of a control group of age-matched healthy subjects. A larger sample would allow for the inclusion of a larger spread in disease severity, symptom ratings on the dyspnea scale, exercise capacity, and comorbidities, and would also allow for a more efficient control of possible mediators, such as age, BMI, and psychological distress. An age-matched control group would help to interpret differences in RA and set boundaries for a normal range. Another limitation is that the dyspnea score was obtained at participants' medical visit closest to the study, which in two cases exceeded 6 months from the study visit. However, the mMRC scale is relatively insensitive to small changes in clinical status and to therapeutic intervention. ${ }^{47,48}$ Inclusion criteria required that only clinically stable patients were enrolled in the study; therefore, the range in assessment time for the mMRC scale should not have had a significant effect on this measure.

\section{Conclusion}

This study is a first step toward the identification of larger rest-activity rhythm amplitude as a marker of better prognosis in COPD and as a potential target for exercise-based rehabilitation programs in this population..$^{49}$ Direction of causality cannot be determined in this study, but regular practice of physical activity may contribute to endogenous circadian amplitude and may have a synchronizing effect on circadian rhythms. ${ }^{32,50,51}$ Beneficial effects of physical activity may thus extend beyond increasing physical fitness, and positively impact on circadian physiology to improve quality of life and decrease mortality in COPD patients.

\section{Acknowledgments}

This research was supported by the Fondation de l'Hôpital du Sacré-Coeur de Montréal (Fonds Auger) and by Concordia University (OVPRGS Seed/Accelerator Funding). Emilie Chan-Thim is the recipient of a doctoral training award from the Fonds de Recherche du Québec - Santé (FRQ-S) and a graduate scholarship from the Campaign for a New Millennium.

\section{Disclosure}

The authors report no conflicts of interest in this work.

\section{References}

1. Pati AK, Parganiha A, Kar A, Soni R, Roy S, Choudhary V. Alterations of the characteristics of the circadian rest-activity rhythm of cancer in-patients. Chronobiol Int. 2007;24(6):1179-1197.

2. Tranah GJ, Blackwell T, Stone KL, et al. Circadian activity rhythms and risk of incident dementia and mild cognitive impairment in older women. Ann Neurol. 2011;70(5):722-732.

3. Hatfield CF, Herbert J, van Someren EJ, Hodges JR, Hastings MH Disrupted daily activity/rest cycles in relation to daily cortisol rhythms of home-dwelling patients with early Alzheimer's dementia. Brain. 2004; 127(5):1061-1074. 
4. Perez-Lloret S, Risk M, Golombek DA, Cardinali DP, Sanchez R, Ramirez A. Blunting of circadian rhythms and increased acrophase variability in sleep-time hypertensive subjects. Chronobiol Int. 2008;25(1): 99-113.

5. Truong KK, Lam MT, Grandner MA, Sassoon CS, Malhotra A. Timing matters: circadian rhythm in sepsis, obstructive lung disease, obstructive sleep apnea, and cancer. Ann Am Thorac Soc. 2016;13(7):1144-1154.

6. Lozano R, Naghavi M, Foreman K, et al. Global and regional mortality from 235 causes of death for 20 age groups in 1990 and 2010: a systematic analysis for the Global Burden of Disease Study 2010. Lancet. 2012;380(9859):2095-2128.

7. Hogg JC. Pathophysiology of airflow limitation in chronic obstructive pulmonary disease. Lancet. 2004;364(9435):709-721.

8. Qaseem A, Wilt TJ, Weinberger SE, et al. Diagnosis and management of stable chronic obstructive pulmonary disease: a clinical practice guideline update from the American College of Physicians, American College of Chest Physicians, American Thoracic Society, and European Respiratory Society. Ann Intern Med. 2011;155(3):179-191.

9. Mannino DM, Doherty DE, Buist AS. Global Initiative on Obstructive Lung Disease (GOLD) classification of lung disease and mortality: findings from the Atherosclerosis Risk in Communities (ARIC) study. Respir Med. 2006;100(1):115-122.

10. Fletcher C, Peto R. The natural history of chronic airflow obstruction. BMJ. 1977;1(6077):1645-1648.

11. Anthonisen NR, Connett JE, Murray RP. Smoking and lung function of Lung Health Study participants after 11 years. Am J Respir Crit Care Med. 2002;166(5):675-679.

12. Vestbo J, Edwards LD, Scanlon PD, et al. Changes in forced expiratory volume in 1 second over time in COPD. N Engl J Med. 2011;365(13): 1184-1192.

13. Donaldson GC, Seemungal TA, Bhowmik A, Wedzicha JA. Relationship between exacerbation frequency and lung function decline in chronic obstructive pulmonary disease. Thorax. 2002;57(10):847-852.

14. Celli BR, Cote CG, Marin JM, et al. The body-mass index, airflow obstruction, dyspnea, and exercise capacity index in chronic obstructive pulmonary disease. N Engl J Med. 2004;350(10):1005-1012.

15. Divo M, Cote C, de Torres JP, et al. Comorbidities and risk of mortality in patients with chronic obstructive pulmonary disease. Am J Respir Crit Care Med. 2012;186(2):155-161.

16. de Torres JP, Casanova C, Marin JM, et al. Prognostic evaluation of COPD patients: GOLD 2011 versus BODE and the COPD comorbidity index COTE. Thorax. 2014;69(9):799-804.

17. Chan-Thim E, Dumont M, Moullec G, et al. Clinical impact of time of day on acute exercise response in COPD. COPD. 2014;11(2): 204-211.

18. Chan-Thim E, Dumont M, Rizk AK, Parwanta Z, Pepin V, Moullec G. Diurnal variations in psychological distress in chronic obstructive pulmonary disease. Rehabil Nurs. Epub 2016 Feb 1.

19. Bromundt V, Köster M, Georgiev-Kill A, et al. Sleep-wake cycles and cognitive functioning in schizophrenia. Br J Psychiatry. 2011;198(4): 269-276.

20. Global Initiative for Chronic Obstructive Lung Disease. Global Strategy for the Diagnosis, Management, and Prevention of COPD. Bethesda (MD): GOLD; 2010.

21. Führer R, Rouillon F. The French version of CES-D: description and translation of the self-report scale. Psychiatry Psychobiol. 1989;4: 163-166.

22. Freeston MH, Ladouceur R, Thibodeau N, Gagnon F, Rhéaume J. [The Beck Anxiety Inventory: psychometric properties of a French translation]. Encephale. 1994;20(1):47-55. French.

23. Mahler DA, Wells CK. Evaluation of clinical methods for rating dyspnea. Chest. 1988;93(3):580-586.

24. Fletcher CM. The clinical diagnosis of pulmonary emphysema; an experimental study. Proc R Soc Med. 1952;49(9):577-584.

25. Miller MR, Hankinson J, Brusasco V, et al. Standardisation of spirometry. Eur Respir J. 2005;26(2):319-338.
26. Quanjer PH, Tammeling GJ, Cotes JE, Pedersen OF, Peslin R, Yernault JC. Lung volumes and forced ventilatory flows. Eur Respir J Suppl. 1993;6 Suppl 16:5-40.

27. Jones NL, Makrides L, Hitchcock C, Chypchar T, McCartney N. Normal standards for an incremental progressive cycle ergometer test. Am Rev Respir Dis. 1985;131(5):700-708.

28. Hansen JE, Sue DY, Wasserman K. Predicted values for clinical exercise testing. Am Rev Respir Dis. 1984;129(2 Pt 2):S49-S55.

29. Cardoso F, Tufanin AT, Colucci M, Nascimento O, Jardim JR. Replacement of the 6-min walk test with maximal oxygen consumption in the BODE index applied to patients with COPD: an equivalency study. Chest. 2007;132(2):477-482.

30. Neder JA, Nery LE, Bagatin E, Lucas SR, Anção MS, Sue DY. Differences between remaining ability and loss of capacity in maximum aerobic impairment. Braz J Med Biol Res. 1998;31(5):639-646.

31. Tabak M, Vollenbroek-Hutten MM, van der Valk PD, van der Palen J, Tönis TM, Hermens HJ. Telemonitoring of daily activity and symptom behavior in patients with COPD. Int J Telemed Appl. 2012; 2012:438736.

32. Van Someren EJ, Lijzenga C, Mirmiran M, Swaab DF. Long-term fitness training improves the circadian rest-activity rhythm in healthy elderly males. J Biol Rhythms. 1997;12(2):146-156.

33. Huang YL, Liu RY, Wang QS, Van Someren EJ, Xu H, Zhou JN. Ageassociated difference in circadian sleep-wake and rest-activity rhythms. Physiol Behav. 2002;76(4-5):597-603.

34. Jean-Louis G, Kripke DF, Ancoli-Israel S, et al. Circadian sleep, illumination, and activity patterns in women: influences of aging and time reference. Physiol Behav. 2000;68(3):347-352.

35. Luik AI, Zuurbier LA, Hofman A, Van Someren EJ, Tiemeier H. Stability and fragmentation of the activity rhythm across the sleep-wake cycle: the importance of age, lifestyle, and mental health. Chronobiol Int. 2013;30(10):1223-1230.

36. Germain A, Kupfer DJ. Circadian rhythm disturbances in depression. Hum Psychopharmacol. 2008;23(7):571-585.

37. Monteleone P, Martiadis V, Maj M. Circadian rhythms and treatment implications in depression. Prog Neuropsychopharmacol Biol Psychiatry. 2011;35(7):1569-1574.

38. Mormont MC, Waterhouse J, Bleuzen P, et al. Marked 24-h rest/activity rhythms are associated with better quality of life, better response, and longer survival in patients with metastatic colorectal cancer and good performance status. Clin Cancer Res. 2000;6(8):3038-3045.

39. Bhullar S, Phillips B. Sleep in COPD patients. COPD. 2005;2(3):355-361.

40. Watz H, Waschki B, Meyer T, Magnussen H. Physical activity in patients with COPD. Eur Respir J. 2009;33(2):262-272.

41. Garcia-Aymerich J, Felez MA, Escarrabill J, et al. Physical activity and its determinants in severe chronic obstructive pulmonary disease. Med Sci Sports Exerc. 2004;36(10):1667-1673.

42. Tudor-Locke C, Washington TL, Hart TL. Expected values for steps/ day in special populations. Prev Med. 2009;49(1):3-11.

43. Mantoani LC, Hernandes NA, Guimarães MM, Vitorasso RL, Probst VS, Pitta F. Does the BODE index reflect the level of physical activity in daily life in patients with COPD? Rev Bras Fisioter. 2011;15(2): 131-137.

44. Partridge MR, Karlsson N, Small IR. Patient insight into the impact of chronic obstructive pulmonary disease in the morning: an internet survey. Curr Med Res Opin. 2009;25(8):2043-2048.

45. Kessler R, Partridge MR, Miravitlles M, et al. Symptom variability in patients with severe COPD: a pan-European cross-sectional study. Eur Respir J. 2011;37(2):264-272.

46. Du-Quiton J, Wood PA, Burch JB, et al. Actigraphic assessment of daily sleep-activity pattern abnormalities reflects self-assessed depression and anxiety in outpatients with advanced non-small cell lung cancer. Psychooncology. 2010;19(2):180-189.

47. van der Molen T, Miravitlles M, Kocks JW. COPD management: role of symptom assessment in routine clinical practice. Int J Chron Obstruct Pulmon Dis. 2013;8:461-471. 
48. Haughney J, Gruffydd-Jones K. Patient-centred outcomes in primary care management of COPD: what do recent clinical trial data tell us? Prim Care Respir J. 2004;13(4):185-197.

49. Spruit MA, Pitta F, McAuley E, ZuWallack RL, Nici L. Pulmonary rehabilitation and physical activity in patients with chronic obstructive pulmonary disease. Am J Respir Crit Care Med. 2015;192(8):924-933.
50. Tranel HR, Schroder EA, England J, et al. Physical activity, and not fat mass is a primary predictor of circadian parameters in young men. Chronobiol Int. 2015;32(6):832-841.

51. Atkinson G, Edwards B, Reilly T, Waterhouse J. Exercise as a synchroniser of human circadian rhythms: an update and discussion of the methodological problems. Eur J App Physiol. 2007;99(4):331-341.

\section{Publish your work in this journal}

ChronoPhysiology and Therapy is an international, peer-reviewed open access journal focusing on research into the cyclic variations and rhythmicity in physiological processes in the body and the research and development and optimal timing of administration of therapeutic targets to achieve improved outcomes and quality of life for the patient. The manuscript management system is completely online and includes a very quick and fair peer-review system. Visit http://www.dovepress.com/ testimonials.php to read real quotes from published authors. 